\title{
Earlier re-evaluation may be possible in pediatric patients with eutopic congenital hypothyroidism requiring lower L-thyroxine doses
}

\author{
Min Sun Cho, MD', \\ Gyung Sun Cho, MD', \\ So Hyun Park, MD, PhD ${ }^{3}$, \\ Min Ho Jung, $\mathrm{MD}, \mathrm{PhD}^{4}$, \\ Byung Kyu Suh, MD, PhD ${ }^{5}$, \\ Dae Gyun Koh, MD, PhD ${ }^{3}$
}

${ }^{1}$ Department of Pediatrics, The Catholic University of Korea, St. Paul's Hospital, Seoul, ${ }^{2}$ Department of Pediatrics, The Catholic University of Korea, Bucheon St. Mary's Hospital, Bucheon, ${ }^{3}$ Department of Pediatrics, The Catholic University of Korea, St. Vincent's Hospital, Suwon, ${ }^{4}$ Department of Pediatrics, The Catholic University of Korea, Yeouido St. Mary's Hospital, Seoul, ${ }^{5}$ Department of Pediatrics, The Catholic University of Korea, Seoul St. Mary's Hospital, Seoul, Korea
Purpose: The incidence of congenital hypothyroidism $(\mathrm{CH})$ has increased in several countries. Lower cut-off in screening programs have led to an increase in the proportion of transient hypothyroidism $(\mathrm{TH})$ cases diagnosed, leading to debate on the associated clinical and economic impact. This study aimed to identify factors that would allow discrimination between $\mathrm{TH}$ and permanent $\mathrm{CH}(\mathrm{PH})$ in patients with a eutopic thyroid gland.

Methods: Sixty-six patients with $\mathrm{CH}$ from 3 different hospitals were studied: 26 cases of $\mathrm{TH}$, and 40 cases of $\mathrm{PH}$. Laboratory findings and clinical parameters were analysed in 56 patients with eutopic thyroid gland.

Results: Initial serum thyroid stimulating hormone levels and L-thyroxine dose at 12 and 24 months of age were significantly higher in $\mathrm{PH}$ than $\mathrm{TH}$ patients with a eutopic thyroid gland. The area under the curve for the 12-month and 24-month dose for the prediction of $\mathrm{TH}$ in eutopic $\mathrm{CH}$ was 0.799 (95\% confidence interval $[\mathrm{Cl}]$, $0.678-0.919 ; P<0.001)$ and 0.925 (95\% Cl, 0.837-1.000; $P<0.001)$, respectively. The optimum 12-month and 24-month dose in predicting TH is $3.25 \mu \mathrm{g} / \mathrm{kg}$ (12-month: sensitivity, $87.1 \%$; specificity, $68.0 \%$; 24 -month: sensitivity $93.5 \%$, specificity $88 \%$ ). Conclusion: Infants with $\mathrm{CH}$ requiring lower L-thyroxine doses $(<3.25 \mu \mathrm{g} / \mathrm{kg})$ are likely to have $\mathrm{TH}$, and thus might be re-evaluated at 12 months or 24 months rather than 3 years of age.

Keywords: Congenital hypothyroidism, Thyroxine, Thyroid gland

\section{Introduction}

In developed countries, the introduction of screening programs for congenital hypothyroidism $(\mathrm{CH})$ has enabled effective detection of this condition in neonates. In response to screening, the prevalence of $\mathrm{CH}$ has increased, particularly for patients with a eutopic (normally located) thyroid gland and a mild elevation in thyroid-stimulating hormone (TSH; hyperthyrotropinemia) ${ }^{1}$. The reasons for this may be related to lower screening thresholds compared to initial values, allowing for more effective detection of $\mathrm{CH}$, and an increase in the number of premature infants as a result of development of reproductive technologies ${ }^{2-4)}$. Thyroid hormones play an important role in early neurodevelopment, and thus the early treatment of hypothyroidism is crucial ${ }^{1,5,6)}$. Although the long-term outcomes of mild hypothyroidism or hyperthyrotropinemia are not yet fully understood, low screening thresholds and early intervention can mean unnecessary or over-treatment of hyperthyrotropinemia or transient hypothyroidism (TH). Permanent $\mathrm{CH}(\mathrm{PH})$ usually results from thyroid dysgenesis (athyreosis, ectopic thyroid), whereas the underlying aetiologies of $\mathrm{TH}$ are not clear; however, suggested factors include iodine deficiency or excessive iodine intake, penetration of maternal thyroid auto-antibodies, preterm delivery, or immaturity of
Received: 27 August, 2014 Revised: 15 September, 2014 Accepted: 24 September, 2014

Address for correspondence: So Hyun Park, MD, PhD

Department of Pediatrics, The

Catholic University of Korea, St.

Vincent's Hospital, 93 Jungbu-

daero, Paldal-gu, Suwon 442-723,

Korea

Tel: +82-31-249-8312

Fax: +82-31-257-9111

E-mail: nicedoc@catholic.ac.kr
ISSN: 2287-1012(Print)

ISSN: 2287-1292(Online) 
thyroid iodine organification ${ }^{7-9)}$. Current guidelines recommend treatment in patients less than 2 weeks of age if their venous free thyroxine (fT4) concentration is lower than average, or if their venous TSH concentration is higher than $20 \mathrm{mU} / \mathrm{L}$, this age threshold is lower than that of previous guidelines ${ }^{1,10)}$. Generally, further investigations on aetiology are not performed at initial diagnosis, and re-evaluation at 3 years of age is recommended; thus, it is possible that patients with TH are for treated longer than necessary ${ }^{1,10)}$. A number of studies have been conducted to determine how best to discriminate between cases of $\mathrm{TH}$ and $\mathrm{PH}$, when treatment should be stopped, and when reevaluation can be performed ${ }^{11-14)}$. Hypothyroidism due to thyroid aplasia and/or ectopic thyroid require L-thyroxine lifelong. Therefore if the infants are documented to have thyroid dysgenesis, L-thyroxine treatment is required. However, in case of hypothyroid infants with eutopic thyroid gland, definitive criteria have not yet been suggested.

In this study, we investigate the differences between $\mathrm{TH}$ and $\mathrm{PH}$ in patients with a eutopic thyroid gland, and attempt to identify factors enabling their distinction.

\section{Materials and methods}

\section{Patients and methods}

Two hundred and sixty-eight children, who underwent a thyroid function test (TFT) owing to suspected $\mathrm{CH}$ (elevated TSH on neonatal screening test or prolonged jaundice) at St. Vincent's Hospital, Bucheon St. Mary's Hospital, and Yeouido St. Mary's Hospital of The Catholic University of Korea between

Table 1. Clinical characteristics of the two groups with eutopic thyroid gland in ultrasonography $(n=56)$

\begin{tabular}{lccc}
\hline Characteristic & TH group & PH group & P-value \\
\hline No. of patients & $25(39.4)$ & $31(60.6)$ & \\
Sex & & & 1.000 \\
$\quad$ Female & $13(52.0)$ & $16(51.7)$ & \\
$\quad$ Male & $12(48.0)$ & $15(48.3)$ & \\
Birth weight (g) & & & 0.277 \\
$\quad<2,500$ & $2(8.0)$ & $6(19.4)$ & \\
$\geq 2,500$ & $23(92.0)$ & $25(80.6)$ & \\
Gestational age $(w k)$ & & & 0.623 \\
$\quad<37$ & $3(12.0)$ & $4(12.9)$ & \\
$\geq 37$ & $22(88.0)$ & $27(87.1)$ & \\
Serum TSH (mU/L) & $60.5 \pm 78.3$ & $89.4 \pm 67.1$ & 0.038 \\
Serum fT4 (pmol/L) & $0.98 \pm 0.48$ & $1.00 \pm 0.48$ & 0.707 \\
Serum T3 $(\mathrm{ng} / \mathrm{mL})$ & $1.3 \pm 0.4$ & $1.8 \pm 3.7$ & 0.478 \\
L-thyroxine dose $(\mu \mathrm{g} / \mathrm{kg})$ & & & \\
Initial & $10.2 \pm 1.8$ & $11.3 \pm 5.5$ & 0.323 \\
12 Months & $3.1 \pm 1.1$ & $4.5 \pm 1.5$ & $<0.001$ \\
24 Months & $2.5 \pm 1.0$ & $4.2 \pm 0.8$ & $<0.001$ \\
\hline
\end{tabular}

Values are presented as number (\%) or mean \pm standard deviation. $\mathrm{TH}$, transient hypothyroidism; $\mathrm{PH}$, permanent hypothyroidism; TSH, thyroid stimulating hormone; fT4, free thyroxine; T3, triiodothyronine.
January 2004 and April 2014 were enrolled in this study. Medical records were reviewed retrospectively, and patients were confirmed as having primary $\mathrm{CH}(\mathrm{TSH}>10 \mathrm{mU} / \mathrm{L}$ and/ or $\mathrm{fT} 4<0.7 \mathrm{ng} / \mathrm{dL}$ in venous blood). L-thyroxine treatment was started immediately in infants diagnosed with primary $\mathrm{CH}$, at a dose of $10-15 \mu \mathrm{g} / \mathrm{kg}$. One hundred and thirty-one patients were confirmed as having primary $\mathrm{CH}$ and treated with L-thyroxine. Of these, 29 patients were excluded owing to incomplete medical records, and a further 36 were excluded as the followup period was less than 3 years. Sixty-six patients with $\mathrm{CH}$ with follow-up at least 3 years after initial diagnosis were included in the final analysis (Fig. 1).

Patients were treated with L-thyroxine until 3 years of age and re-evaluated after 4 weeks of discontinuing medication; followup was carried out at least 4 years from the initial diagnosis. Thyroid ultrasonography or a Technetium-99 (Tc-99m) thyroid scan was performed either at diagnosis or at the 3-year followup. Either thyroid ultrasonography and/or a thyroid scan were performed to identify patients with thyroid dysgenesis. Thyroid scans were conducted on 27 patients and ultrasonography on 65; however, one patient with TH underwent neither. Nine patients with PH had thyroid agenesis or dysplasia: 4 of these had thyroid agenesis, 2 had agenesis with an ectopic sublingual thyroid gland, and 3 had thyroid hypoplasia. Ultrasonography showed that 56 patients had a eutopic thyroid gland. These were subsequently divided into 2 groups, TH (transient eutopic hypothyroidism: TSH $<5 \mathrm{mU} / \mathrm{L}$ ) and $\mathrm{PH}$ (permanent eutopic hypothyroidism: TSH $>10 \mathrm{mU} / \mathrm{L}$ ). Follow-up was carried out every 1-3 months for patients with hyperthyrotropinemia (TSH, 5-10 mU/L). These patients were all defined as having

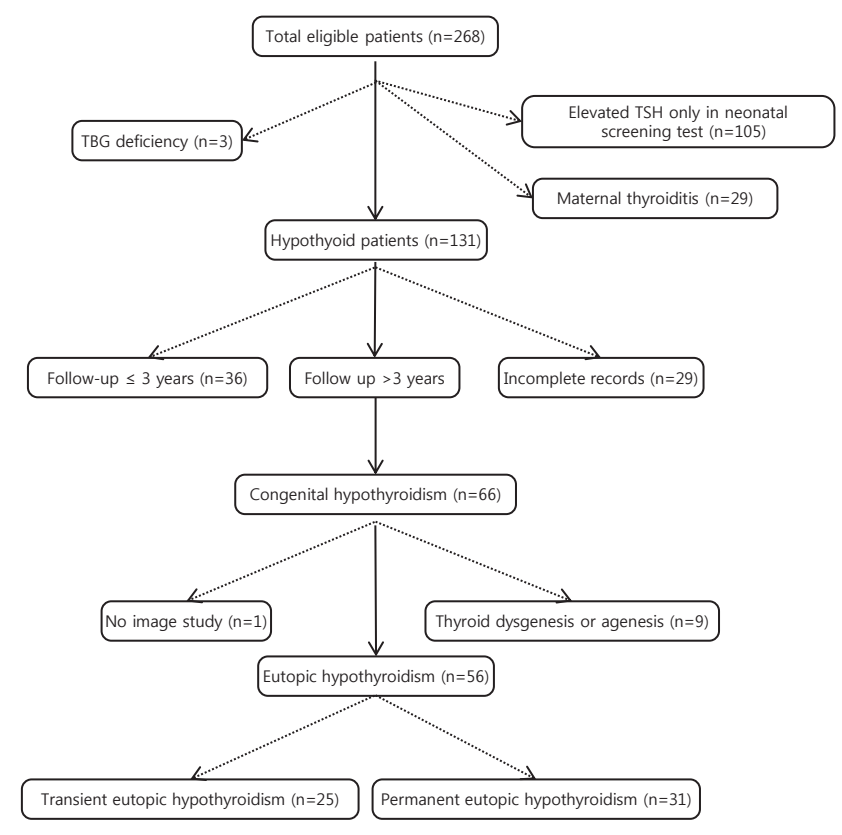

Fig. 1. Flow diagram of the study population with congenital hypothyroidism. TBG, thyroxine binding globulin; TSH, thyroid-stimulating hormone. 
either $\mathrm{PH}$ or TH after the follow-up period. The TH group contained patients for whom treatment could be discontinued at the 3-year follow-up, and the PH group contained patients for whom treatment continued (Fig. 1, Table 1).

All patients were monitored 1 month after L-thyroxine discontinuation, and every 6 months thereafter. Serum triiodothyronine (T3), fT4, and TSH levels were measured by chemiluminescent microparticle immunoassay with the Architect i2000 analyser (Abbott, Abbott Park, IL, USA). Reference values were as follows: T3. $0.58-1.9 \mathrm{ng} / \mathrm{mL}$; fT4, 0.7$1.79 \mathrm{ng} / \mathrm{dL}$; and TSH, $0.35-4.95 \mu \mathrm{IU} / \mathrm{mL}$. L-thyroxine dose per kilogram body weight was calculated at the onset of treatment, at 12 months of age (12M dose), and at 24 months of age (24M dose).

This study complied with the recommendations of the Declaration of Helsinki and was approved by the Institutional Review Boards of St. Vincent's Hospital, Bucheon St. Mary's Hospital, and Yeouido St. Mary's Hospital of The Catholic University of Korea.

\section{Statistical analysis}

Statistical analyses were performed with PASW Statistics ver. 18.0 (SPSS Inc., Chicago, IL, USA). Continuous variables were expressed as the mean \pm standard deviation. Continuous data were analysed using the Student $t$-test and Mann-Whitney test, and categorical variables using the chi-square test or Fisher exact test. A receiver operating characteristic (ROC) curve was designed to estimate the optimum cut-off value in dosage per kilogram for indicating $\mathrm{PH}$. Sensitivity and specificity for this optimum value in the estimation of $\mathrm{PH}$ were calculated. The optimum cut-off value was defined as the highest Youden index [(specificity+sensitivity)-1]. $P$-values lower than 0.05 were considered statistically significant.

\section{Results}

\section{Analysis of patients with a eutopic thyroid gland}

Of the 56 study patients, 25 patients were assigned to the $\mathrm{TH}$ group and 31 patients to the $\mathrm{PH}$ group. None of the patients had associated malformations. Baseline clinical and laboratory values for patients with eutopic thyroid gland are presented in Table 1 . The ratio of female to male patients in both groups was similar as 1.1:1. Low birth weight infants accounted for $8.0 \%$ of the TH group and $19.4 \%$ of the PH group. Premature infants was $12.0 \%$ of the TH group and $12.9 \%$ of the PH group. Initial serum TSH levels were higher in the $\mathrm{PH}$ group than the TH group $(89.4 \pm 67.1$ $\mathrm{mU} / \mathrm{L}$ vs. $60.5 \pm 78.3 \mathrm{mU} / \mathrm{L}, P=0.038$ ) (Table 1 ). Initial serum fT4 and T3 levels were not significantly different between groups. Both the $12 \mathrm{M}$ dose and $24 \mathrm{M}$ dose were higher in the $\mathrm{PH}$ group than the TH group (12M dose: $4.5 \pm 1.5 \mu \mathrm{g} / \mathrm{kg}$ vs. $3.1 \pm 1.1 \mu \mathrm{g} / \mathrm{kg}$, $P<0.001 ; 24 \mathrm{M}$ dose: $4.2 \pm 0.8 \mu \mathrm{g} / \mathrm{kg}$ vs. $2.5 \pm 1.0 \mu \mathrm{g} / \mathrm{kg}, P<0.001$ ) (Table 1).

\section{Estimation of the optimum cut-off dose of $L$-thyroxine for prediction of $\mathrm{TH}$ in patients with a eutopic thyroid gland}

The ROC curves predicting TH using initial TSH level, 12M dose, and 24M dose are shown in Fig. 2. The area under the curve (AUC) for initial TSH for the prediction of TH was 0.662 (95\% confidence interval $[\mathrm{CI}], 0.518-0.806 ; P=0.039$ ), and the optimum cut-off value for initial TSH was $28.4 \mathrm{mU} / \mathrm{L}$ (sensitivity, $80.6 \%$; specificity, $52 \%$ ) (Fig. 2). The AUC for the $12 \mathrm{M}$ dose for the prediction of TH was 0.799 (95\% CI, 0.678-0.919; $P<0.001$ ), and the optimum cut-off value, based on the maximum Youden index, was $3.25 \mu \mathrm{g} / \mathrm{kg}$ (sensitivity, 87.1\%; specificity, 68.0\%) (Fig. 2). $12 \mathrm{M}$ dose of the highest sensitivity (100\%) was $1.9 \mu \mathrm{g} / \mathrm{kg}$, and that of the highest specificity (100\%) was $5.55 \mu \mathrm{g} / \mathrm{kg}$. The AUC for $24 \mathrm{M}$ dose for the prediction of TH was 0.925 (95\% CI, $0.837-1.000 ; P<0.001)$, The optimum cut-off value of $24 \mathrm{M}$ dose was $3.25 \mu \mathrm{g} / \mathrm{kg}$ (sensitivity, $93.5 \%$; specificity, $88 \%$ ). Additionally, $24 \mathrm{M}$ dose of the highest sensitivity (100\%) was $2.8 \mu \mathrm{g} / \mathrm{kg}$ and that of the highest specificity (100\%) was $5.0 \mu \mathrm{g} / \mathrm{kg}$.

\section{Discussion}

In the present study, the prevalence of TH was $39.4 \%$, which is comparable with that in other recent studies which showed values of $38 \%-54.9 \%^{11,12,15-17)}$. Based on this information, more

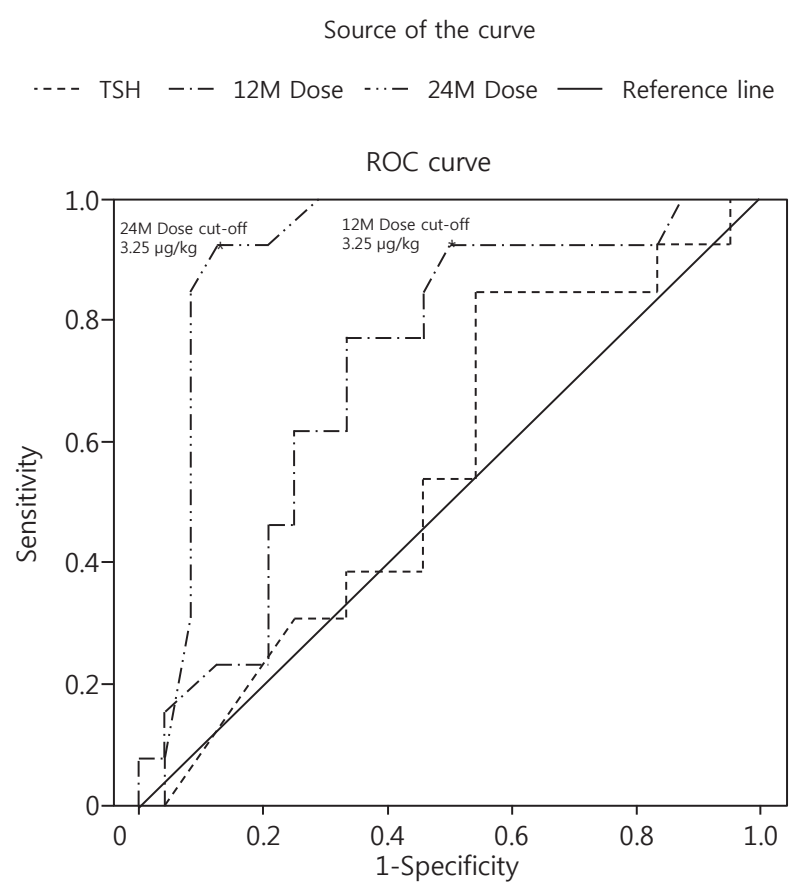

Fig. 2. Receiver operating characteristic (ROC) curve of initial serum TSH, L-thyroxine dose at 12 months of age (12M dose), and 24 months of age (24M dose) reflecting transient congenital hypothyroidism. The cutoff values of $12 \mathrm{M}$ dose and $24 \mathrm{M}$ dose were $3.25 \mathrm{\mu g} / \mathrm{kg}$ (area under the curve $=0.799 ; 95 \% \mathrm{Cl}, 0.678$ 0.919; $P<0.001$; sensitivity, $87.1 \%$; specificity, $68.0 \%$ ) and $3.25 \mu \mathrm{g} / \mathrm{kg}$ (area under the curve $=0.925 ; 95 \% \mathrm{Cl}, 0.837-1.000 ; P<0.001$; sensitivity, $93.5 \%$; specificity, $88 \%)$, respectively. $\mathrm{TSH}$, thyroid-stimulating hormone; $\mathrm{Cl}$, confidence interval. 
than one-third of $\mathrm{CH}$ cases do not require lifelong medication. Therefore, markers that would allow early detection of TH are required.

In this retrospective review of pediatric patients with $\mathrm{CH}$ with a eutopic thyroid gland, initial venous TSH concentration, 12M dose, and $24 \mathrm{M}$ dose were significantly higher in $\mathrm{PH}$ than $\mathrm{TH}$ cases. Among these patients, a $12 \mathrm{M}$ and $24 \mathrm{M}$ dose $>3.25 \mu \mathrm{g} / \mathrm{kg}$ indicated a higher chance of developing PH. Current guidelines recommend the administration of $10-15 \mu \mathrm{g} / \mathrm{kg}$ of L-thyroxine after the initial diagnosis of $\mathrm{CH}$, followed by dose titration at 1 to 3-month intervals to maintain a venous TSH concentration within the average range ${ }^{1)}$. Hong et al. ${ }^{11)}$ states that the only difference between $\mathrm{PH}$ and $\mathrm{TH}$ is the L-thyroxine dose required. They showed that required doses are significantly lower in $\mathrm{TH}$ than in PH at 6 months, 12 months, 24 months, and 36 months of age, with doses of $3.3 \pm 1.2 \mu \mathrm{g} / \mathrm{kg}$ for TH and $4.8 \pm 1.3 \mu \mathrm{g} / \mathrm{kg}$ for $\mathrm{PH}$ at 12 months of age. Unuvar et al. ${ }^{12)}$ also suggest that only L-thyroxine dose can be used to distinguish between TH and $\mathrm{PH}$, with values of $2.8 \pm 1.19 \mu \mathrm{g} / \mathrm{kg}$ for $\mathrm{TH}$ and $4.07 \pm 1.88 \mu \mathrm{g} / \mathrm{kg}$ for $\mathrm{PH}$ at 12 months of age given. These doses are comparable to those described here; however, their study population contained patients with thyroid dysgenesis, and the authors did not suggest an optimum cut-off dose in predicting TH. Thus, to the best of our knowledge, our study is the first to suggest a cut-off dose of L-thyroxine that would allow discrimination between babies with $\mathrm{TH}$ and $\mathrm{PH}$ in eutopic $\mathrm{CH}$.

TSH concentrations in venous blood at initial diagnosis were higher for $\mathrm{PH}$ than $\mathrm{TH}$ in this study. This has also been shown in several other studies ${ }^{12,17-19)}$. Lim et al. ${ }^{17)}$ suggest a cutoff TSH level of $34 \mathrm{mU} / \mathrm{L}$ (sensitivity, 72\%; specificity, 93\%) for the prediction of $\mathrm{PH}$. In the present study, cut-off TSH level was $28.4 \mathrm{mU} / \mathrm{L}$ with slightly higher sensitivity and lower specificity than that of Lim et al. ${ }^{17}$. On the other hand, Rabbiosi et al. ${ }^{16)}$ suggest there is no difference in TSH concentration between $\mathrm{PH}$ and $\mathrm{TH}$, although initial TSH concentrations might vary depending on when the blood sample was drawn. If the sampling was carried out too early, TSH levels may not have been sufficiently elevated. Therefore, TSH concentration at initial diagnosis cannot accurately predict the severity of $\mathrm{CH}$.

Several reports have suggested that preterm and low birth weight infants have a higher tendency to have $\mathrm{TH}^{20-24)}$. Preterm, low birth weight infants are usually critically ill and vulnerable to neurodevelopmental disability. Thus, even if their thyroid dysfunction is transient, L-thyroxine treatment is necessary. In the present study, 6 of the 9 preterm or low birth weight infants had PH. However, our results were not significant in predicting $\mathrm{TH}$ or PH.

Otherwise, the prevalence of thyroid dyshormonogenesis was $75 \%$ ( 31 from 40 patients with $\mathrm{PH}$ ). It is various from $31.3 \%$ to $76.9 \%$ in several studies ${ }^{11,12,17,25)}$. These wide variety of prevalence might be due to the various ethnicity and whether perchlorate discharge test was done or not. We did not conduct perchlorate discharge test to infants with eutopic thyroid gland.

In contrast to past standards, current guidelines recommend early treatment with L-thyroxine (where possible at less than 2 weeks of age) when the venous TSH concentration is $>20 \mathrm{mU} /$ L irrespective of fT 4 concentration, and "playing safe" by treating with L-thyroxine during early childhood when TSH levels are low $(6-20 \mathrm{mU} / \mathrm{L})$ and $\mathrm{fT} 4$ levels are normal ${ }^{1)}$. In addition, once treatment is started, re-evaluation is not recommended until 3 years of age or older. This is based on the fact that myelination of the brain is completed by $36-40$ months of age ${ }^{26)}$, and that the child may be more co-operative during imaging. Thyroid scans require sedation, intravenous access, and should be carried out at least 5 days after L-thyroxine administration begins, and thus cannot be easily conducted for neonates at the initial diagnosis of $\mathrm{CH}$. However, ultrasonography is not invasive, and can be easily performed for neonates, although it cannot identify dyshormonogenesis. Therefore, we suggest that neonates with a high likelihood of developing $\mathrm{CH}$ be treated immediately, and undergo thyroid ultrasonography. If the infants have thyroid dysgenesis, re-evaluation can be delayed until 3 years of age or over. According to the present study, the patients with eutopic thyroid gland requiring L-thyroxine $>5.55 \mu \mathrm{g} / \mathrm{kg}$ at 12 months or $>5.0 \mu \mathrm{g} / \mathrm{kg}$ have highly suggestive of $\mathrm{PH}$, they should not be decreased the dose or carefully re-evaluated at 3 years of age. Patients requiring lower L-thyroxine doses tend to have $\mathrm{TH}$ at the re-evaluation of 3 years of age in some studies ${ }^{16,25}$. Furthermore, if patients requiring lower than $1.9 \mu \mathrm{g} / \mathrm{kg}$ at 12 months and lower than $2.8 \mu \mathrm{g} / \mathrm{kg}$ at 24 months can be transient hypothyroidism in the present study. These patients could be tapered the dosage of L-thyroxine at 12 months or 24 months easily. In the present study if infants have a eutopic thyroid gland, and L-thyroxine doses $<3.25 \mu \mathrm{g} / \mathrm{kg}$ are required at 12 months and 24 months of age, re-evaluation may be performed carefully by decreasing the dose of L-thyroxine by $30 \%$ for $2-3$ weeks, and rechecking by TFT ${ }^{1}$. This study has several limitations. It involved a retrospective review of medical records. Although patients from 3 different hospitals were included, the relatively small study population hindered significance in our analyses. In addition, the sensitivity and specificity for the cutoff with the highest Youden index of the 12M and 24M dose in predicting $\mathrm{PH}$ were not particularly high; therefore, it cannot be used as a definitive standard. Further long-term studies on the benefits of L-thyroxine treatment in $\mathrm{TH}$ in relation to neurodevelopment are also required.

The results of this study suggest that infants with $\mathrm{CH}$ who require lower L-thyroxine doses by 12 months and 24 months of age are likely to have $\mathrm{TH}$. Therefore, infants with $\mathrm{CH}$ requiring lower L-thyroxine doses $(3.25 \mu \mathrm{g} / \mathrm{kg}$ at 12 months and 24 months) may be re-evaluated at 12 months or 24 months rather than 3 years of age by decreasing the dose of L-thyroxine.

\section{Conflict of interest}

No potential conflict of interest relevant to this article was reported. 


\section{References}

1. Leger J, Olivieri A, Donaldson M, Torresani T, Krude H, van Vliet G, et al. European Society for Paediatric Endocrinology consensus guidelines on screening, diagnosis, and management of congenital hypothyroidism. J Clin Endocrinol Metab 2014;99:363-84.

2. Deladoey J, Ruel J, Giguere Y, Van Vliet G. Is the incidence of congenital hypothyroidism really increasing? A 20-year retrospective population-based study in Québec. J Clin Endocrinol Metab 2011;96:2422-9.

3. Sakka SD, Malamitsi-Puchner A, Loutradis D, Chrousos GP, Kanaka-Gantenbein C. Euthyroid hyperthyrotropinemia in children born after in vitro fertilization. J Clin Endocrinol Metab 2009;94:1338-41.

4. Radetti G, Fanolla A, Pappalardo L, Gottardi E. Prematurity may be a risk factor for thyroid dysfunction in childhood. J Clin Endocrinol Metab 2007;92:155-9.

5. Zoeller RT, Tan SW, Tyl RW. General background on the hypothalamic-pituitary-thyroid (HPT) axis. Crit Rev Toxicol 2007;37:11-53.

6. Horn S, Heuer H. Thyroid hormone action during brain development: more questions than answers. Mol Cell Endocrinol 2010;315:19-26.

7. Bhavani N. Transient congenital hypothyroidism. Indian J Endocrinol Metab 2011;15(Suppl 2):S117-20.

8. Vermiglio F, Lo Presti VP, Scaffidi Argentina G, Finocchiaro MD, Gullo D, et al. Maternal hypothyroxinaemia during the first half of gestation in an iodine deficient area with endemic cretinism and related disorders. Clin Endocrinol (Oxf) 1995;42:409-15.

9. Hashemipour M, Hovsepian S, Kelishadi R, Iranpour R, Hadian R, Haghighi S, et al. Permanent and transient congenital hypothyroidism in Isfahan-Iran. J Med Screen 2009;16:11-6.

10. American Academy of Pediatrics, Rose SR; Section on Endocrinology and Committee on Genetics, American Thyroid Association, Brown RS; Public Health Committee, Lawson Wilkins Pediatric Endocrine Society, Foley T, et al. Update of newborn screening and therapy for congenital hypothyroidism. Pediatrics 2006;117:2290-303.

11. Hong SY, Chung HR, Lee SY, Shin CH, Yang SW. Factors distinguishing between transient and permanent hypothyroidism in patients diagnosed as congenital hypothyroidism by newborn screening. J Korean Soc Pediatr Endocrinol 2005;10:154-60.

12. Unuvar T, Demir K, Abaci A, Buyukgebiz A, Bober E. The role of initial clinical and laboratory findings in infants with hyperthyrotropinemia to predict transient or permanent hypothyroidism. J Clin Res Pediatr Endocrinol 2013;5:1703.

13. Zung A, Tenenbaum-Rakover Y, Barkan S, Hanukoglu A, Hershkovitz E, Pinhas-Hamiel O, et al. Neonatal hyperthy- rotropinemia: population characteristics, diagnosis, management and outcome after cessation of therapy. Clin Endocrinol (Oxf) 2010;72:264-71.

14. Skordis N, Toumba M, Savva SC, Erakleous E, Topouzi M, Vogazianos M, et al. High prevalence of congenital hypothyroidism in the Greek Cypriot population: results of the neonatal screening program 1990-2000. J Pediatr Endocrinol Metab 2005;18:453-61.

15. Kohler B, Schnabel D, Biebermann H, Gruters A. Transient congenital hypothyroidism and hyperthyrotropinemia: normal thyroid function and physical development at the ages of 6-14 years. J Clin Endocrinol Metab 1996;81:15637.

16. Rabbiosi S, Vigone MC, Cortinovis F, Zamproni I, Fugazzola L, Persani L, et al. Congenital hypothyroidism with eutopic thyroid gland: analysis of clinical and biochemical features at diagnosis and after re-evaluation. J Clin Endocrinol Metab 2013;98:1395-402.

17. Lim HK, Kim KH, Kim SH, No HY, Kim CJ, Woo YJ, et al. Predictors of transient hypothyroidism in neonatal screening test. J Korean Soc Pediatr Endocrinol 2006;1 1:506.

18. Ghasemi M, Hashemipour M, Hovsepian S, Heiydari K, Sajadi A, Hadian R, et al. Prevalence of transient congenital hypothyroidism in central part of Iran. J Res Med Sci 2013;18:699-703.

19. Unuvar T, Demir K, Abac1 A, Atas A, Buyukgebiz A, Bober E. Monitoring and prognostic evaluation of patients with congenital hypothyroidism treated in a pediatric endocrinology unit. Turk J Pediatr 2013;55:384-90.

20. Lim G, Lee YK, Han HS. Early discontinuation of thyroxine therapy is possible in most very low-birthweight infants with hypothyroidism detected by screening. Acta Paediatr 2014;103:e123-9.

21. Srinivasan R, Harigopal S, Turner S, Cheetham T. Permanent and transient congenital hypothyroidism in preterm infants. Acta Paediatr 2012;101:e179-82.

22. Chung HR, Shin CH, Yang SW, Choi CW, Kim BI, Kim EK, et al. High incidence of thyroid dysfunction in preterm infants. J Korean Med Sci 2009;24:627-31.

23. Chee YY, Wong KY, Low L. Review of primary hypothyroidism in very low birthweight infants in a perinatal centre in Hong Kong. J Paediatr Child Health 2011;47:824-31.

24. Bijarnia S, Wilcken B, Wiley VC. Newborn screening for congenital hypothyroidism in very-low-birth-weight babies: the need for a second test. J Inherit Metab Dis 2011;34:827-33.

25. Eugster EA, LeMay D, Zerin JM, Pescovitz OH. Definitive diagnosis in children with congenital hypothyroidism. J Pediatr 2004;144:643-7.

26. Parazzini C, Baldoli C, Scotti G, Triulzi F. Terminal zones of myelination: MR evaluation of children aged 20-40 months. AJNR Am J Neuroradiol 2002;23:1669-73. 